Exerting self-control induces a narrow mindset

Sabrina Bruyneel and Siegfried Dewitte

DEPARTMENT OF MARKETING AND ORGANISATION STUDIES (MO) 


\title{
Exerting Self-Control Induces a Narrow Mindset
}

\author{
Sabrina Bruyneel ${ }^{1}$ and Siegfried Dewitte \\ Katholieke Universiteit Leuven
}

Self-control theories have focused on various aspects of the processes involved in exerting self-control. In the present paper, we intend to add to this literature by demonstrating that exerting self-control leads one to narrow one's attention and cognition, inducing a narrow mindset. We demonstrate this in three studies. Participants who exerted self-control applied a narrower view (Study 1), applied a narrower categorization (Study 2), and used more concrete language (Study 3) than participants who did not exert self-control. Results are discussed in light of the possibility that a narrow mindset enhances performance on the self-control task at hand at the cost of poorer performance on other tasks.

Keywords: self-control, broad mindset, narrow mindset, depletion

Acknowledgements

Financial support by a university grant (OT/03/07), the National Science Foundation (G.0391.03), and Censydiam-Synovate are gratefully acknowledged. The authors thank all members of the consumer behavior group at the Katholieke Universiteit Leuven for helpful comments on an earlier version of this manuscript.

\footnotetext{
${ }^{1}$ Corresponding author. Sabrina Bruyneel, Naamsestraat 69, 3000 Leuven, Belgium, Tel.: +32 1632 69 47, Fax: + 32163267 32, E-mail address: sabrina.bruyneel@econ.kuleuven.be
} 
The capacity to exert self-control is an important feature of human nature. Self-control refers to the self's capacity to alter its own responses. In general, people are able to regulate their thoughts, control their emotions, alter their performance or inhibit their impulses (e.g., Baumeister, Bratslavsky, Muraven, \& Tice, 1998). Selfcontrol theories have focused on various aspects of the processes involved in exerting self-control. Amongst other conceptualizations, researchers have stressed the importance of balancing 'hot' and 'cool' cognitions (Metcalfe \& Mischel, 1999), short-term and long-term considerations (Wertenbroch, 1998), low-level and highlevel construals (Fujita, Trope, Liberman, \& Levin-Sagi, in press), or visceral responses and rational self-interest (Loewenstein, 1996) in the processes involved in self-control. Yet others have focused on the energetic nature of self-control (Baumeister et al., 1998), the distinction between automatic versus controlled psychological processes (Bargh \& Chartrand, 1999), and the role of perceptions of self-efficacy (Bandura, 1991) in exerting self-control. In the present paper, we intend to add to this literature by focusing on yet another aspect of the processes involved in self-control. More specifically, we argue that exerting self-control leads one to narrow one's attention and cognition, inducing a narrow mindset.

Challenging tasks and narrowing of attention and cognition

Earlier, it has been argued that narrowing one's attention and cognition is associated with more successful performance on challenging tasks, particularly in the initial stages of learning (e.g., Mischel, Cantor, \& Feldman, 1996; Norman \& Shallice, 1986; Scheier \& Carver, 1988; Vallacher \& Wegner, 1987; Vallacher, Wegner, \& Somoza, 1989). Experientially, a number of different sorts of tasks such as those involving planning, decision-making, and components of troubleshooting, those being ill-learned or containing novel sequences of actions, those being judged to be technically difficult, those requiring the overcoming of a strong habitual or emotional response, and those requiring resisting temptation, necessitate deliberate attentional resources (Norman \& Shallice, 1986). In the delay of gratification paradigm for instance, suppression of attention to the rewards facilitates successful delay behavior (Mischel et al., 1996). According to action identification theory, encoding difficult activities using low levels of abstraction and thus focusing attention towards task details enhances performance on the difficult task at hand (Vallacher et al., 1989; Vallacher \& Wegner, 1987). 
Task circumstances that are highly similar to the ones just mentioned have been identified as involving a lot of self-control (e.g., Vohs \& Baumeister, 2004). Hence, we propose that self-control tasks will also lead to narrowing of attention and cognition. More specifically, we claim that the exertion of self-control will even induce a narrow mindset, in that the state of narrowed attention and cognition lingers and influences how people deal with subsequent tasks.

Broad and narrow mindsets, and the link with self-control

We propose a distinction between broad and narrow mindsets. Previously, mindsets have been defined as a heightened accessibility of cognitive operations (Gollwitzer, 1990), whereby recently used cognitive operations are assumed to have temporarily higher activation levels, thus increasing their likelihood of being used to interpret new information (cf. Higgins, 1996) or steering behavior (Gollwitzer \& Bayer, 1999). Gollwitzer and colleagues (e.g., Gollwitzer, 1990; Gollwitzer \& Bayer, 1999) distinguished deliberative (i.e., considering potential pros and cons of particular courses of actions) and implemental mindsets (i.e., planning how to carry out activities). Besides differences in cognitive tuning and biased inferences, people in deliberative mindsets have also been found to differ from people in implemental mindsets in openness to information (Fujita, Gollwitzer, \& Oettingen, in press). Freitas, Gollwitzer, and Trope (2004) discriminated between abstract (i.e., construing actions at high levels of abstraction, specifying why they are performed) and concrete mindsets (i.e., construing actions at low levels of abstraction, specifying how they are performed), thus drawing on both action identification theory (Vallacher \& Wegner, 1987; Vallacher et al., 1989) and construal theory (Fujita, Trope, et al., in press; Trope \& Liberman, 2000).

We propose that exertion of self-control and the broadness of one's mindset are linked. Most of the conceptualizations above have been linked to self-control issues before. What they basically have in common is that they assume importance of balancing abstract, long-term aims with concrete, immediate experiences in selfcontrol issues. In fact, there is a lot of literature stating that balancing long-term, abstract aims and immediate, concrete experiences constitutes the essence of selfcontrol (e.g., Mischel, Shoda, \& Rodriguez, 1989; Rachlin, 2000; Trope \& Fishbach, 2000). We want to look at the link between broadness of mindset and self-control from another angle, however. Rather than assuming that people need a certain mindset 
in order to exert self-control, we propose that the act of exerting self-control induces a certain mindset in people. As indicated before, as successful performance on tasks that have important features in common with typical self-control tasks (e.g., Vohs \& Baumeister, 2004) has been found to rely on narrowing of attention and cognition (e.g., Mischel et al., 1996; Norman \& Shallice, 1986; Scheier \& Carver, 1988; Vallacher et al., 1989; Vallacher \& Wegner, 1987), we propose that the exertion of self-control will also rely on narrowing of attention and cognition, and will even induce a narrow mindset.

The present studies

It has been shown that the tendency to construe situations in a certain way can be activated by using similar construals in unrelated prior contexts (e.g., Förster, Friedman, \& Lieberman, 2004) or can be induced directly through manipulations that activate cognitive procedures associated with each respective construal (Freitas et al., 2004). Hence, if we are right in assuming that the exertion of self-control induces a narrow mindset, we should be able to observe carry-over effects of self-control manipulations on broadness of one's attention and cognition for subsequent ostensibly unrelated tasks.

In three experiments, we manipulated self-control and assessed the broadness of participants' mindset. We chose a "legal brief” approach in which we attempted to summon evidence for our hypothesis using a package of disparate experiments (cf. Baumeister et al., 1998). If exerting self-control induces a narrow mindset, participants who have exerted self-control should adopt a narrow view (Study 1), apply narrow categorization (Study 2), and use concrete language (Study 3). We used various self-control tasks and various measures of broadness of mindset as a first step towards generalization. Both the self-control tasks (e.g., Kuhl \& Kazen, 1999; Muraven \& Slessareva, 2003; Wallace \& Baumeister, 2002; Wegner, Ansfield, \& Pilloff, 1998) and the measures of broadness of mindset (Gollwitzer \& Bayer, 1999; Liberman, Sagristano, \& Trope, 2002; Semin, Higgins, Gil de Montes, Estourget, \& Valencia, 2005) have been well-established in previous literature.

\section{Study 1}

In Study 1, participants engaged in a task that either required self-control or not. Subsequently, participants watched a series of slides that displayed centrally and 
peripherally presented information, and performed an unexpected recognition test containing the information presented (Gollwitzer \& Bayer, 1999). If exerting selfcontrol induces a narrow mindset, participants who have exerted self-control should correctly recognize fewer peripherally but more centrally presented words than participants who have not exerted self-control.

\section{Method}

Participants were 65 undergraduate students (45 women). They received a participation fee.

Participants were asked to engage in a thought-listing task for five minutes. They were instructed to write down their thoughts and either to avoid thinking about a white bear (self-control condition) or to think about anything they wanted, including a white bear (no self-control condition). When thinking of a white bear in the selfcontrol condition, participants had to immediately change their thoughts and try very hard not to think of a white bear again. A similar task proved to be a successful selfcontrol manipulation in earlier research (e.g., Muraven \& Slessareva, 2003).

Subsequently, they watched a series of slides centrally displaying meaningful sentences and peripherally (i.e., in the upper left-hand and lower right-hand corners) displaying unrelated nouns. Participants were instructed to make a story out of the centrally displayed sentences. No mention of the peripherally presented nouns was made prior to the task. Later on, participants performed an unexpected recognition test containing 10 centrally presented nouns (i.e., nouns appearing in the centrally displayed sentences), 10 peripherally presented nouns, and 10 previously not presented nouns. A similar task provided a successful measure of broadness of focus in earlier research (e.g., Gollwitzer \& Bayer, 1999).

Participants' mood was assessed by means of the Positive Affect Negative Affect Schedule (PANAS; Watson, Clark, \& Tellegen, 1988). This was done to validate that mood states were not different depending on self-control condition, thus ruling out a possible alternative account for our findings. Indeed, negative mood states have been shown to be associated with more systematic processing (Bless, Bohner, Schwarz, \& Strack, 1990), and hence might influence the broadness of one’s mindset. 
Results

We counted the number of nouns that were recognized correctly. Two participants who did not follow instructions were removed from further analyses. As predicted, participants who had exerted self-control recognized fewer peripherally presented nouns correctly $(M=3.21, S D=2.26)$ than participants who had not exerted self-control $(M=4.50, S D=2.25), t(61)=-2.27, p=.03$, but participants who had exerted self-control recognized more centrally presented nouns correctly ( $M$ $=6.97, S D=2.04)$ than participants who had not exerted self-control $(M=5.26, S D=$ 2.79), $t(61)=2.72, p=.01$. This suggests that exerting self-control induces a narrow mindset. No differences between self-control conditions were observed for previously not presented nouns (self-control: $M=9.34, S D=0.97$; no self-control: $M=9.35, S D$ $=0.92 ; t(61)=-0.03, p=.97)$.

The effect of self-control on narrowness of focus cannot be explained by mood differences. Levels of positive (self-control: $M=26.83$, $S D=5.61$; no self-control: $M$ $=27.91, S D=5.69 ; t(61)=-0.76, p=.45)$ and negative affect (self-control: $M=$ 16.00, $S D=5.97$; no self-control: $M=15.76, S D=4.66 ; t(61)=0.18, p=.86$ ) did not differ between self-control conditions. Moreover, adjusting for positive and negative affect as covariates did not change the pattern of results reported above, suggesting that mood does not mediate the effect of self-control on narrowness of focus.

\section{Study 2}

In Study 2, participants engaged in a task that either required self-control or not. Subsequently, participants imagined themselves in one of three situations (e.g., having a yard sale) and classified objects related to each situation (e.g., books, cutlery) in as many categories as they deemed suitable (Liberman et al., 2002). Forming fewer groups means applying broader, more abstract categorization, whereas forming more groups means applying narrower, more concrete categorization. If exerting self-control induces a narrow mindset, participants who have exerted selfcontrol should form more groups than participants who have not exerted self-control. 


\section{Method}

Participants were 63 undergraduate students (47 women). They received a participation fee.

Participants were asked to engage in the same thought-listing task as in Study 1. Subsequently, participants imagined that they were going on a camping trip, that they were going to be moving into a new apartment, or that they were going to have a yard sale. Each scenario came with 38 objects that participants had to place into groups (e.g., tent and matches in the camping scenario, VCR and computer in the moving out scenario, and roller blades and board games in the yard sale scenario). This task is one of the standard measures of broadness of categorization (e.g., Liberman et al., 2002).

Participants' mood was assessed by means of the PANAS (Watson et al., 1988). This was done to validate that mood states were not different depending on self-control condition.

\section{Results}

We counted the number of groups into which participants classified the objects of each scenario. We collapsed over scenarios. As predicted, participants who had exerted self-control formed more groups $(M=6.82, S D=1.70)$ than participants who had not exerted self-control $(M=6.00, S D=1.41), t(61)=2.06, p=.04$. This suggests that exerting self-control induces a narrow mindset.

The effect of self-control on narrowness of categorization cannot be explained by mood differences. Levels of positive (self-control: $M=24.29, S D=5.46$; no selfcontrol: $M=26.40, S D=6.78 ; t(59)=-1.34, p=.19$ ) and negative affect (selfcontrol: $M=14.61, S D=6.24$; no self-control: $M=13.90, S D=5.03 ; t(59)=0.49, p$ $=.63$ ) did not differ between self-control conditions. Moreover, adjusting for positive and negative affect as covariates did not change the pattern of results reported above, suggesting that mood does not mediate the effect of self-control on narrowness of categorization.

\section{Study 3}

In Study 3, participants engaged in a task that either required self-control or not. We used a different self-control task for reasons of generalization. Subsequently, 
participants watched a series of five cartoons and described what they saw in writing, using one single word for each cartoon. Words were analyzed for abstractness of language, using coding schemes developed for the Linguistic Categorization Model (Semin \& Fiedler, 1998). Broader, more abstract ways of thinking should be revealed through the use of more abstract language, whereas narrower, more concrete ways of thinking should be revealed through the use of more concrete language. If exerting self-control induces a narrow mindset, participants who have exerted self-control should use more concrete language than participants who have not exerted selfcontrol.

\section{Method}

Participants were 106 undergraduate students (86 women). They received a participation fee.

Participants were asked to engage in a variation of the Stroop task and to indicate the ink color of 50 color names. Words and ink colors were either matched (e.g., RED in red ink; no self-control condition) or mismatched (e.g., RED in yellow ink; self-control condition). In addition, in the self-control condition, in case a word in blue ink appeared (i.e., in 25\% of the trials), participants were instructed to indicate the word rather than the ink color. A similar task proved to be a successful selfcontrol manipulation in earlier research (Wallace \& Baumeister, 2002).

Subsequently, participants watched a series of five cartoons and described the behavior of each cartoon's main character using one single word. Two judges blind to condition coded participants' written descriptions according to the Linguistic Categorization Model (Semin \& Fiedler, 1988). According to this model, four linguistic categories (i.e., descriptive action verbs, interpretative action verbs, state verbs, and adjectives) can be organized along a dimension of concreteness to abstractness, with descriptive action verbs being the least, and adjectives being the most abstract. Typically, a weighting schema is applied to weigh descriptive action verbs (1), interpretative action verbs (2), state verbs (3), and adjectives (4) (Semin \& Smith, 1999). Words describing the cartoon rather than its main character's actions (i.e., $4 \%$ of the words) were omitted from the analysis. To control for these missing values, weighted scores were divided by the number of coded predicates for each participant. The resulting abstractness index scores (ranging from 1 to 4) calculated from each judge's ratings were highly correlated, $r=.94, p<.0001$. Discrepancies in 
codes were resolved through discussion to form a single index. This task is one of the standard measures of linguistic abstraction (e.g., Semin et al., 2005).

Participants' mood was assessed by means of the PANAS (Watson et al., 1988). This was done to validate that mood states were not different depending on self-control condition.

Results

We averaged the standardized abstractness index scores across cartoons. Codes were standardized to control for the fact that some cartoons were perceived to be more abstract than others. As predicted, participants who had exerted self-control used more concrete language $(M=-0.08, S D=0.60)$ than participants who had not exerted self-control $(M=0.20, S D=0.78), t(104)=-2.06, p=.04$. This suggests that exerting self-control induces a narrow mindset.

The effect of self-control on linguistic abstraction cannot be explained by mood differences. Levels of positive (self-control: $M=29.30, S D=6.15$; no selfcontrol: $M=28.46, S D=4.31 ; t(104)=0.81, p=.42$ ) and negative affect (selfcontrol: $M=13.02, S D=3.73$; no self-control: $M=12.96, S D=3.45$; $t(104)=0.08$, $p=.94$ ) did not differ between self-control conditions. Moreover, adjusting for positive and negative affect as covariates did not change the pattern of results reported above, suggesting that mood does not mediate the effect of self-control on linguistic abstraction.

\section{General discussion}

In three experiments, we tested the hypothesis that exerting self-control induces a narrow mindset. Participants who exerted self-control by suppressing their thoughts applied a narrower view (Study 1) and narrower categorization (Study 2) than participants who did not suppress their thoughts and hence did not exert selfcontrol. In Study 3, participants who exerted self-control by inhibiting their dominant responses during a taxing Stroop task used more concrete language than participants who did not inhibit their dominant responses during an easy Stroop task and hence did not exert self-control. In a meta-analysis on our findings, we calculated a difference score for the two dependent variables of interest in Study 1, and reversed scores such that lower values indicated a narrower mindset for all dependent measures. Next, we standardized our dependent measures and aggregated the findings across all three 
studies $(\mathrm{N}=232)$. Participants who exerted self-control provided evidence of a narrower mindset $(M=-0.26, S D=0.91)$ than participants who did not exert selfcontrol $(M=0.26, S D=1.01), t(230)=4.12, p<.0001$. These findings suggest that a narrow mindset is a consequence of engaging in self-control that consistently occurs after various instances of self-control.

In the present paper, we proposed a distinction between broad and narrow mindsets. Similar differentiations have emerged in previous literature. Examples are concepts such as high level and low level action identifications (Vallacher \& Wegner, 1987), high level and low level construals (Trope \& Liberman, 2000), simultaneous and sequential decision making (Simonson, 1990), distributed and isolated decision making (Herrnstein \& Prelec, 1992), broad and narrow decision frames (Kahneman \& Lovallo, 1993), decision making based on patterns and acts (Rachlin, 1995), overall and local value functions (Heyman, 1996), and broad and narrow bracketing (Read, Loewenstein, \& Rabin 1999). Broad bracketing (i.e., like high level action identifications, high construals, simultaneous decision making, distributed decision making, broad decision framing, pattern-based decision making, considering overall value functions) allows people to take into account all the consequences of their actions, whereas narrow bracketing (i.e., like low level action identifications, low construals, sequential decision making, isolated decision making, narrow decision framing, act-based decision making, and considering local value functions) induces people to make each decision in isolation (Read et al., 1999).

We sought to provide a unified account of these constructs by advancing a distinction between broad and narrow mindsets. We preferred to use the term mindset over the terms bracketing or construal, because, similar to the term mindset as used by Gollwitzer (1990), the state that we describe lingers and influences how people deal with subsequent tasks. Simultaneously, the term mindset is associated with temporality and, like other momentarily activated cognitive material, can be expected to dissolve gradually over time (e.g., Higgins, 1996). We preferred to use the term mindset over the terms action identification level, decision making, or value function because the term mindset does not only reflect action perception, decision making, or utility calculations, but has implications for all of these constructs. Likewise, we preferred to use the terms broad and narrow over some of the other adjectives mentioned, because, similar to the adjectives broad and narrow as used by Read et al. (1999), the state that we describe induces general changes in one’s breadth of 
attention, shifting people's attention from the macro level to the micro level, or the other way around.

We found that a narrow mindset consistently occurs after various instances of self-control. These results might have implications for research about another consequence of exerting self-control, namely, self-control depletion. It has been argued that all acts of self-control draw on a common limited resource that is akin to energy or strength. Hence, exertion of self-control is necessarily followed by a period of diminished capacity to exert subsequent self-control (i.e., depletion). Eventually, with sufficient rest, the resource should build up again (Baumeister et al., 1998; Muraven, Tice, \& Baumeister, 1998). Given the present findings, it might very well be that narrow mindsets and self-control depletion are related phenomena. Although narrowing one's focus down to concrete task characteristics appears to be functional to adequately perform the self-control task at hand (Vallacher et al., 1989), it might not be functional to adequately perform a subsequent self-control task that requires a different focus. The narrow mindset that is induced as a way to deal with the first task does not vanish immediately, rendering the participant relatively unable to deal successfully with the second task. According to Gollwitzer (1990), the transfer of cognitive procedures from one task to an unrelated task is the hallmark of mindset priming. The traditional self-control depletion effect then (i.e., people do not perform well on self-control tasks after having exerted self-control previously) might result from the detrimental effects of the prolonged mindset induced by the first self-control task on the second self-control task. This line of reasoning nevertheless implies that the narrow mindset resulting from exerting self-control is content-specific to some extent, which is a fundamental assumption that remains to be investigated.

Ironically, the above line of reasoning would mean that a narrow mindset might sometimes be beneficial, and sometimes be detrimental for successful selfcontrol, the latter assertion being consistent with recent literature (Fujita, Trope, et al., in press). Fujita, Trope, et al. (in press) manipulated construal levels and assessed self-control subsequently. They showed that high level construals, in comparison to low level construals, increased self-control. We proceeded the other way around, in that we manipulated self-control exertion and assessed the broadness of one's mindset subsequently. Seemingly contradictory to Fujita, Trope, et al. (in press), we observed that having exerted self-control, in comparison to not having exerted self-control, induced a more narrow mindset. These combined findings again hint at how mindsets 
might provide an explanation for the typical depletion effect. Although previous induction of a broad way of thinking is beneficial for self-control later on (Fujita, Trope, et al., in press), the very act of exerting self-control induces one to narrow one's attention and cognition, making subsequent self-control more difficult. More research is needed however to clarify the exact nature of the moderating factor that determines when a narrow mindset is beneficial or detrimental for self-control. 


\section{References}

Bandura, A. (1991). Social cognitive theory of self-regulation. Organizational Behavior and Human Decision Processes, 50, 248-287.

Bargh, J. A., \& Chartrand, T. L. (1999). The unbearable automaticity of being. American Psychologist, 54, 462-479.

Baumeister, R. F., Bratslavsky, E., Muraven, M., \& Tice, D. M. (1998). Ego depletion: Is the active self a limited resource? Journal of Personality and Social Psychology, 74, 1252-1265.

Bless, H., Bohner, G., Schwarz, N., \& Strack, F. (1990). Mood and persuasion: A cognitive response analysis. Personality and Social Psychology Bulletin, 16, 331-345.

Förster, J., Friedman, R. S., \& Liberman, N. (2004). Temporal construal effects on abstract and concrete thinking: Consequences for insight and creative cognition. Journal of Personality and Social Psychology, 87, 177-189.

Freitas, A. L., Gollwitzer, P. M., \& Trope, Y. (2004). The influence of abstract and concrete mindsets on anticipating and guiding others' self-regulatory efforts. Journal of Experimental Social Psychology, 40, 739-752.

Fujita, K., Gollwitzer, P. M., \& Oettingen, G. (in press). Mindsets and pre-conscious open-mindedness to incidental information. Journal of Experimental Social Psychology.

Fujita, K., Trope, Y., Liberman, N., \& Levin-Sagi, M. (in press). Construal levels and self-control. Journal of Personality and Social Psychology.

Gollwitzer, P. M. (1990). Action phases and mind-sets. In E. T. Higgins \& R. M. Sorrentino (Eds.), Handbook of motivation and cognition: Foundations of social behavior (Vol. 2, pp. 53-92). New York: The Guilford Press.

Gollwitzer, P. M., \& Bayer, U. (1999). Deliberative versus implemental mindsets in the control of action. In S. Chaiken \& Y. Trope (Eds.), Dual-process theories in social psychology (pp. 403-422). New York: The Guilford Press.

Herrnstein, R. J., \& Prelec, D. (1992). A theory of addiction. In G. F. Loewenstein \& J. Elster (Eds.), Choice over time. New York: Russell Sage Foundation.

Heyman, G. M. (1996). Resolving the contradictions of addiction. Behavioral and Brain Sciences, 19, 561-610.

Higgins, E. T. (1996). Knowledge activation: Accessibility, applicability, and 
salience. In E. T. Higgins \& A. W. Kruglanski (Eds.), Social psychology: Handbook of basic principles (pp. 133-168). New York: The Guilford Press. Kahneman, D., \& Lovallo, D. (1993). Timid choices and bold forecasts: A cognitive perspective on risk taking. Management Science, 39, 17-31.

Kuhl, J., \& Kazen, M. (1999). Volitional facilitation of difficult intentions: Joint activation of intentions memory and positive affect removes stroop interference. Journal of Experimental Psychology: General, 128, 382-399.

Liberman, N., Sagristano, M. D., \& Trope, Y. (2002). The effect of temporal distance on level of mental construal. Journal of Experimental Social Psychology, 38, 523-534.

Loewenstein, G. F. (1996). Out of control: Visceral influences on behavior. Organizational Behavior and Human Decision Processes, 65, 272-292.

Metcalfe, J., \& Mischel, W. (1999). A hot/cool-system analysis of delay of gratification: Dynamics of will power. Psychological Review, 106, 3-19.

Mischel, W., Cantor, N., \& Feldman, S. (1996). Principles of self-regulation: The nature of willpower and self-control. In E. T. Higgins \& A. W. Kruglanski (Eds.), Social Psychology. Handbook of basic principles (pp. 329-360). New York: The Guilford Press.

Mischel, W., Shoda, Y., \& Rodriguez, M. L. (1989). Delay of gratification in children. Science, 244, 933-938.

Muraven, M., \& Slessareva, E. (2003). Mechanisms of self-control failure: Motivation and limited resources. Personality and Social Psychology Bulletin, 29, 894906.

Muraven, M., Tice, D. M., \& Baumeister, R. F. (1998). Self-control as a limited resource: Regulatory depletion patterns. Journal of Personality and Social Psychology, 74, 774-789.

Norman, D. A., \& Shallice, T. (1986). Attention to action. Willed and automatic control of behavior. In R. J. Davidson, G. E. Schwartz, \& D. Shapiro (Eds.), Consciousness and self-regulation, Volume 4 (pp. 1-18). New York: Plenum Press.

Rachlin, H. (1995). Self-control: Beyond commitment. Behavioral and Brain Sciences, 18, 109-159.

Rachlin, H. (2000). The science of self-control. Cambridge, MA: Harvard University Press. 
Read, D., Loewenstein, G., \& Rabin, M. (1999). Choice bracketing. Journal of Risk and Uncertainty, 19, 171-197.

Scheier, M. F. \& Carver, C. S. (1988). A model of behavioral self-regulation: Translating intention into action. In L. Berkowitz (Ed.), Advances in Experimental Social Psychology, 21 (pp. 303-346). New York: Academic Press.

Semin, G. R., \& Fiedler, K. (1998). The cognitive functions of linguistic categories in describing persons: Social cognition and language. Journal of Personality and Social Psychology, 54, 558-568.

Semin, G. R., Higgins, E. T., Gil de Montes, L., Estourget, Y., \& Valencia, J. (2005). Linguistic signatures of regulatory focus: How abstraction fits promotion more than prevention. Journal of Personality and Social Psychology, 89, 36-45.

Semin, G. R., \& Smith, E. R. (1999). Revisiting the past and back to the future: Memory systems and the linguistic representation of social events. Journal of Personality and Social Psychology, 76, 877-892.

Simonson, I. (1990). The effect of purchase quantity and timing on variety seeking behavior. Journal of Marketing Research, 32, 150-162.

Trope, Y., \& Fishbach, A. (2000). Counteractive self-control in overcoming temptation. Journal of Personality and Social Psychology, 78, 493-506.

Trope, Y., \& Liberman, N. (2000). Temporal construal and time-dependent changes in preference. Journal of Personality and Social Psychology, 79, 876-889.

Vallacher, R. R. , \& Wegner, D. M. (1987). What do people think they're doing? Action identification and human behavior. Psychological Review, 94, 3-15.

Vallacher, R. R., Wegner, D. M., \& Somoza, M. P. (1989). That's easy for you to say: Action identification and speech fluency. Journal of Personality and Social Psychology, 56, 199-208.

Vohs, K.D., \& Baumeister, R.F. (2004). Ego-depletion, self-control, and choice. In J. Greenberg, S. L. Koole, \& T. Pyszczynski (Eds.), Handbook of experimental existential psychology (pp. 398 - 410). New York: Guilford Press.

Wallace, H. M., \& Baumeister, R. F. (2002). The effects of success versus failure feedback on further self-control. Self and Identity, 1, 35-41.

Watson, D., Clark, L. A., \& Tellegen, A. (1988). Development and validation of brief 
measures of positive and negative affect: The PANAS scales. Journal of Personality and Social Psychology, 54, 1063-1070.

Wegner, D.M., Ansfield, M., \& Pilloff, D. (1998). The putt and the pendulum: Ironic effects of the mental control of action. Psychological Science, 9, 196-199.

Wertenbroch, K. (1998). Consumption self-control by rationing purchase quantities of virtue and vice. Marketing Science, 17, 317-337. 